\title{
Arts-based assessment in educational settings
}

\author{
Jiř́ Kantor ${ }^{1}$, Xianmei Lei ${ }^{2}$ \\ ${ }^{1}$ Institute of Special Educational Studies, Palacký University, Czech Republic \\ ${ }^{2}$ College of Special Education, Leshan Normal University, China
}

\begin{tabular}{ll} 
Article Info & ABSTRACT \\
\cline { 2 - 3 } Article history: & $\begin{array}{l}\text { Arts-based assessment is an objective measure that incorporates artistic } \\
\text { experience or artistic materials into the assessment process and enables to get } \\
\text { unique contributions about pupils. The current survey focused on arts-based } \\
\text { Received Oct 5, 2019 }\end{array}$ \\
assessment in the Czech Republic to explore the following issues: how did \\
arts therapists assess suitability of therapy for pupils; which areas of \\
therapeutic process were evaluated and what made the process of arts-based
\end{tabular}

This is an open access article under the CC BY-SA license.

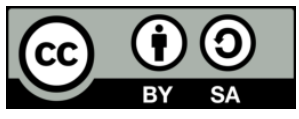

\section{Corresponding Author:}

Xianmei Lei,

College of Special Education,

Leshan Normal University,

778 Binhe Road, Shizhong District, Leshan, Sichuan Province, China.

Email: xianmei.lei@qq.com

\section{INTRODUCTION}

Based on the definition of Betts [1] arts-based assessment can be defined as an objective (standardised or non-standardised) measure that incorporates artistic experience or artistic materials into the assessment process. Over the past two decades, much attention has been paid to reviewing arts-based assessments for the client populations or areas of practice [2], new examples of scientifically based tests were introduced [3-5], and the validity and reliability of some existing assessments were improved [6-8]. To date, little attention has been devoted to the analysis of arts-based assessments in less common areas of therapeutic practice, for example in schools.

The main fields of arts therapies include art therapy, music therapy, drama therapy and dancemovement therapy. In each field of arts therapy, arts-based assessment has different historical roots and further developments [9] that had to respond to the needs of therapeutic practice, the gradual shaping of the professional status of the field, and to the requirements of the institutions and clinical population. Additionally, some common characteristics of arts-based assessment pertain to all fields of arts therapies: Formalised assessments in arts therapies increasingly shift emphasis from the analysis of symbols 
(assessment of the content) to analysing formal characteristics of artistic expression (based on searching for specific clusters of these elements and their context across different tested situations). Examples include tests created by Cohen \& Mills [10], or Lipský [11]. Therapeutic assessment is very distant from the traditional diagnostic "testing" based on relational neutrality, objectivity and manualised evaluation process [12]. Some tests in arts therapies have an explicit stimulus character and serve to initiate an intervention [13, 14]. Although some assessments are primarily based on a particular theory, e.g. attachment theory [15], most assessments combine different theoretical influences [16] or even claim theoretical neutrality [10]. Computer technologies influence the development of arts-based assessments, particularly in the field of art therapy [17-19] and music therapy [20]. One of the most discussed topics of arts-based assessment is the need for standardisation. There are reasons for and objections against the standardisation, and both sets of views are supported by relevant reasons [1].

From an interdisciplinary perspective, the importance of the conclusions of arts-based assessments is based on offering diverse, but also complementary information that can be gained by a high degree of interaction during examination. The use of arts-based assessments in schools is based on a number of unique reasons. One reason for assessment is to predict if arts therapies may help to achieve optimal learning outcomes for pupils with special needs [21]. Another reason is the benefit of these assessments for pupils with a higher degree of special needs who cannot be tested by traditional test methods [22, 23]. Arts-based assessments evaluate overall development, interaction and arts involvement.

In the Czech Republic, arts therapies are not registered as independent professions and are usually practiced as a supplement to other professions [24]. A large percentage of arts therapists in educational institutions have a primary qualification in special education or school psychology. Czech arts therapists were traditionally employed in special schools and in the process of assessment could collaborate with psychologists, physiotherapists, occupational therapists and other professionals from interdisciplinary teams [25]. In 2016 the Ministry of Education released a new law that definitively supported the transformation of educational systems towards inclusive education. Therefore, a shift of Czech arts therapists into typical schools may be expected in the near future.

This trend will probably further reduce the opportunity of team collaboration during the assessment process, as inclusive environments in the Czech Republic lack the variety of rehabilitation services typical for special schools [26]. In such a situation a new challenge and responsibility arises for arts therapists. They must be able to carry out the process of assessment on their own and contribute significantly to the knowledge of pupils, their problems and strengths, and the functioning of pupils in the school environment. In turn this change should significantly influence training programmes in arts therapies, strengthen the role of arts-based assessment and the development of special practices to alleviate the needs of educational settings. Sufficient knowledge of current practice in arts-based assessment in educational institutions is essential for effective support of arts therapists by professional associations, universities and private courses. Because such knowledge is not available in the Czech Republic, a study was devised and carried out to analyse the current practice in arts-based assessment typical for educational institutions in the Czech Republic.

\section{RESEARCH METHOD}

\subsection{Objectives and design of the study}

The research method designed by Karkou and Sanderson [27] (working in the field of arts therapies in Great Britain) was used. Due to the need to acquire heterogeneous data, the quantitative section of this methodology was supplemented by qualitative analysis according to the sequence model of mixed design [28]. For the quantitative section two hypotheses were formulated: 1)What do the arts therapists assess when considering the suitability of therapy for clients?; 2) Which areas the arts therapists evaluate in the final phase of the therapeutic process? For the qualitative section a research question was conceptualised: What characteristics are typical for the process of arts-based assessments in educational institutions?

In the quantitative section the original questionnaire "The Practice of Arts Therapies" [27] was adapted for use in the Czech environment and distributed through professional associations to practising arts therapists. The questionnaire has five sections (A-E), of which section D contains four items allotted for assessment/evaluation with the possibility of multiple choices. The other sections focus on general information relating to the practice, theoretical influences, therapeutic principles, and essential biographical information about respondents. The original questionnaire version had to be updated mainly in the items related to professional qualifications. The questionnaire was processed by statistical analysis through the use of MS Excel and Statistica 12 program. The research sample was divided into a subgroup of respondents from educational institutions and respondents from other working environments. A combination of the number of absolute and relative frequencies was used to identify the prevalent tendencies in both the 
subgroups of respondents. The percentage ratios of relative frequencies were counted from all answers of respondents.

Data collection for the qualitative part of the research was carried out through semi-structured interviews with arts therapists from educational institutions. Each interview was undertaken personally and lasted approximately $60 \mathrm{~min}$. The interviews focused on 2 main topics: 1) Professional development of participants, e.g. university education, artistic education, various trainings and courses or professional interest for future development; 2) Context and course of the arts-based assessment, e.g. theoretical background of assessment, role and character of artistic/verbal experience in the assessment, different artistic materials/instruments/styles, typical therapeutic goals and assessment procedures.

Inductive thematic analysis was used to identify characteristic features of arts-based assessment in educational institutions. The analysis process was carried out in several steps, including reading and segmenting the text, identifying themes, and content coding. For this procedure the following definitions of themes and codes were used [29]: 1) A theme is a unit of meaning that is observed in the data by a reader of the text; 2) The identification of themes precedes the identification of codes, because codes represent a greater level of abstraction than themes, and a single theme can engender multiple codes; 3) Meta-themes are conceptually comprised of two or more data-driven themes that correspond to content codes. They are at a higher level of abstraction and are not directly observed in the data. During the process of coding, three general sets of aims were addressed [30]: examining commonalities, differences, and relationships.

\subsection{Research sample}

The research sample in the quantitative analysis consisted of 142 respondents, whilst the qualitative group included 10 participants. For reasons mentioned above (absence of law and/or the professionalisation of arts therapies), it was difficult to set up the inclusivity and exclusivity criteria, particularly in the quantitative section. Finally, the participation in the research was limited to practising arts therapists in the area of the Czech Republic (there were 419 members registered in professional organisations, some of whom do not actively practice arts therapies - data updated on 31.1.2017). The questionnaire was sent to all members of the professional associations (by the purposive sampling method), and the respondents were asked to forward it to arts therapists who are not registered in associations (by the snowball sampling method). This ensured that the selection was neither too narrow (number of members who meet professional standards is too small, as the professional standards of the associations are not legally binding), nor too wide. Participants of training programmes were also included among the respondents if they already had some practical experience in arts therapies.

The selection for the qualitative part was based on purposive sampling selection through professional associations, recommendations from arts therapists and selection from personal contacts. In this part the inclusive criteria was further limited only to those arts therapists who practice in educational institutions as their main work environment. Therapists with long-term practice and high erudition were given preference; however, the group was also supplemented by participants who could offer inspirational stimuli in the research data.

\subsubsection{Quantitative sample}

Table 1 represents the numbers of respondents according to the directions of arts therapies. The ratio of arts therapies directions corresponds to the number of directions of arts therapies in practice (according to the number of members in professional associations). Apart from the main directions of arts therapies, there is a further category of respondents who combine arts therapies (corresponding to the intermodal concept of expressive therapies that is very influential in the Czech Republic).

Categorised by working environment, there were 51 respondents from educational institutions and 91 from other work environment. Other characteristics of the research sample: 1) In total, there were 117 women and 25 men (of which 43 women and 8 men came from educational institutions). 2) Based on age groups: 41 to 50 years $(35.2 \%)$ and 31 to $40(29.6 \%)$, and by the length of experience, the category 4 to 7 years $(28.9 \%)$ and up to 3 years $(23.9 \%)$ were the most represented categories in the whole sample, as well in the educational institution subgroup. 3) In terms of qualifications, 54 were fully qualified arts therapists (37.7\%), 27 were participants in training programmes (19\%) and 61 were respondents (43\%) who consider themselves to be other professionals using the arts therapies were in the group. Also, here the numbers in the subgroup of respondents from educational institutions corresponded to trends in the whole sample. 
Table 1. Numbers of respondents in a questionnaire survey

\begin{tabular}{cccc}
\hline Specialisations of arts therapies & Respondents & Respondents: educational institutions & Respondents: other institutions \\
\hline Music therapy & $50(35.2 \%)$ & $20(14.1 \%)$ & $30(21.1 \%)$ \\
Art therapy & $38(26.8 \%)$ & $14(9.9 \%)$ & $24(16.9 \%)$ \\
Combinations of arts therapies & $36(25.4 \%)$ & $14(9.9 \%)$ & $7(4.9 \%)$ \\
Drama therapy & $9(6.3 \%)$ & $2(1.4 \%)$ & $8(5.6 \%)$ \\
Dance movement therapy & $9(6.3 \%)$ & $1(0.7 \%)$ & $22(15.5 \%)$ \\
Total & $142(100 \%)$ & $51(35.9 \%)$ & $91(64.1 \%)$ \\
\hline
\end{tabular}

\subsubsection{Qualitative sample}

There were seven music therapists, two drama therapists and one art therapist included in the qualitative group. There were four males and six females were within the group, namely arts therapists with either a qualification in special education (six), other pedagogical education (two) and/or psychology (two). From the point of view of the type of educational institution, most of the participants had jobs at more than one institution at a time, including elementary schools (nine), typical (inclusive) schools (eight), kindergartens (seven), special schools (seven), and schools for artistic education (one). Eight participants were external employees, while only two participants had a full-time job in an educational institution.

\section{RESULTS AND DISCUSSION}

The quantitative section focused on two issues related to assessment/evaluation according to hypotheses from section 2.1. Arts therapies offered by each therapist are suitable for clients under certain conditions. According to the results of the whole group of respondents (all working environments), it is most important that both the therapist and the client feel they can work together (13.7\% of responses) and that the client feels settled within an enabling environment (12.6\% of responses). From these items, it is clear that an important precondition for the therapeutic process is a well-developed therapeutic alliance and the assessments most frequently fall within the category of therapeutic assessments which is consistent with trends in the practice of arts therapists abroad [9, 12]. Somewhat less important items are related to the specific qualities of artistic means and artistic processes: responsiveness to the artistic means (11.7\%), and using arts as a channel for emotional outlet (9.2\%). The lowest frequency of responses was given to items that are primarily related to the psychodynamic and insight-oriented-concepts of therapy: the ability to symbolise, to work with unconscious processes or using words as defence against feelings.

Table 2 contains frequencies for criteria used to assess the suitability of arts therapies in educational/other working environment. In educational institutions, the most common criterion appears to be the feeling that the therapist and the client are able to work together (4.8\%); also the fact that the client feels settled in an enabling environment (4.5\%) and that the client responds to artistic means (4.4\%), etc. These criteria also appear in a subgroup of others - the benchmark criterion for situations where the client has the problem of finding words for his/her feelings is at the top.

Table 2. Criteria for assessing the suitability of therapy according to the work environment

\begin{tabular}{ccc}
\hline Criteria for assessing the suitability of therapy & Educational institutions & Others \\
\hline Client is responsive to artistic medium & $35(4.4 \%)$ & $58(7.3 \%)$ \\
Client is very well motivated & $18(2.3 \%)$ & $38(4.8 \%)$ \\
We both feel we can work together & $38(4.8 \%)$ & $71(8.9 \%)$ \\
Client feels settled within an enabling environment & $36(4.5 \%)$ & $64(8 \%)$ \\
There is a need for emotional outlet & $26(3.3 \%)$ & $47(5.9 \%)$ \\
Client is able to work spontaneously & $23(2.9 \%)$ & $28(3.5 \%)$ \\
Client is able to symbolise & $14(1.8 \%)$ & $11(1.4 \%)$ \\
Client has communication problems & $34(4.3 \%)$ & $55(6.9 \%)$ \\
Client struggles to find words for his/her feelings & $20(2.5 \%)$ & $68(8.5 \%)$ \\
Client uses words as defence against his/her feelings & $13(1.6 \%)$ & $35(4.4 \%)$ \\
Client is able to work with his/her unconscious processes & $10(1.3 \%)$ & $24(3 \%)$ \\
Others reasons & $3(0.4 \%)$ & $4(0.5 \%)$ \\
\hline
\end{tabular}

In addition, areas for therapeutic work evaluation are essential for therapeutic processes because they provide proof about its effectivity. Within the whole group of respondents, the general areas for therapeutic work evaluation permeate the different therapy methods, for example, evaluation of verbal/nonverbal communication (12.1\%), changes in behaviour $(11.1 \%)$, engagement with therapeutic process $(10.6 \%)$, etc. Specific areas usually associated with certain therapeutic approaches, such as the evaluation of transference/countertransference $(4.6 \%)$, neurological issues $(2.2 \%)$, or resistance to work 
(1.3\%), are less commonly assessed. Additional comments in the open items related to the close linking of the assessment process with the therapeutic process and the development of the therapeutic relationship, and the focus on the positive aspects of personality and empowerment of the client.

Table 3 shows the results of the analysis of arts therapists from educational/other working environments. The highest frequencies again correspond to the frequency distribution across the whole group. When comparing the individual items across each type of institution, educational institutions have the highest frequency of use of facilities, evaluation of favoured instruments/media, development of art work and changes in behaviour. Additionally, items that are typical for other institutions have the lowest frequencies, such as the evaluation of neurological issues, transference/counter-transference, dynamic issues.

Table 3. Areas of therapeutic work evaluation according to the working environment

\begin{tabular}{ccc}
\hline Areas of therapeutic work evaluation & Educational institutions & Others \\
\hline Ability to use facilities & $26(3.2 \%)$ & $31(3.4 \%)$ \\
Favoured instruments/media & $28(3.4 \%)$ & $38(4.6 \%)$ \\
Development of the art work & $22(2.7 \%)$ & $22(2.7 \%)$ \\
Emerged issues & $22(2.7 \%)$ & $48(5.8 \%)$ \\
Dynamic issues & $17(2.1 \%)$ & $31(3.4 \%)$ \\
Verbal/non-verbal communication & $34(4.1 \%)$ & $66(8 \%)$ \\
Transference/counter-transference & $9(1.1 \%)$ & $29(3.5 \%)$ \\
Coping mechanisms & $10(1.2 \%)$ & $19(2.3 \%)$ \\
Resistance to work & $5(0.6 \%)$ & $6(0.7 \%)$ \\
Engagement with therapy process & $31(3.4 \%)$ & $56(6.8 \%)$ \\
Neurological issues & $5(0.6 \%)$ & $12(1.5 \%)$ \\
Changes in behaviour & $34(4.1 \%)$ & $57(6.9 \%)$ \\
Key issues for the client & $20(2.4 \%)$ & $50(6.1 \%)$ \\
Client's perception of progress & $31(3.4 \%)$ & $56(6.8 \%)$ \\
Others & $2(0.2 \%)$ & $3(0.4 \%)$ \\
\hline
\end{tabular}

The characteristics of assessment found in both analyses of the quantitative part correspond with the preference of humanistic trends in the Czech arts therapies. Humanistic orientation is the most widely spread across all the fields of Czech arts therapies whereas psychodynamic trends are the least preferred [31]. Humanistic orientation is typical also for other countries where "The Practice in Arts Therapies" questionnaire was used - Great Britain [27] and Latvia [32]. However, the data from these studies about the assessment part of the questionnaire are only partially available which is not sufficient for more detailed comparison.

The results of the qualitative section are summarised in Table 4. Several thematic areas created through the thematic analysis include nature of assessment, methods and procedures used in assessment, content of the assessment, organisation of assessment proces (with the perspectives of time and data docummentation) and other themes. Participants described mostly qualitative, non-standardised assessments, although several examples of published assessments with lower levels of standardisation have been found in the data set $[11,33]$. However, based on current knowledge, such types of assessments are not widespread in the Czech Republic. The only exception are dance movement therapists, for whom the Laban Movement Analysis training is an obligatory part of the training. Some participants from educational institutions admit that assessment is often not an obligatory requirement, and they carry it out for their own needs. However, this finding is not unique to the Czech Republic only [34]. It is the responsibility of professional associations and guarantors of university courses in arts therapies to highlight the importance to systematically carry out assessment or to even create guidelines for arts-based assessment in various settings. 
Table 4. Thematic areas of qualitative part

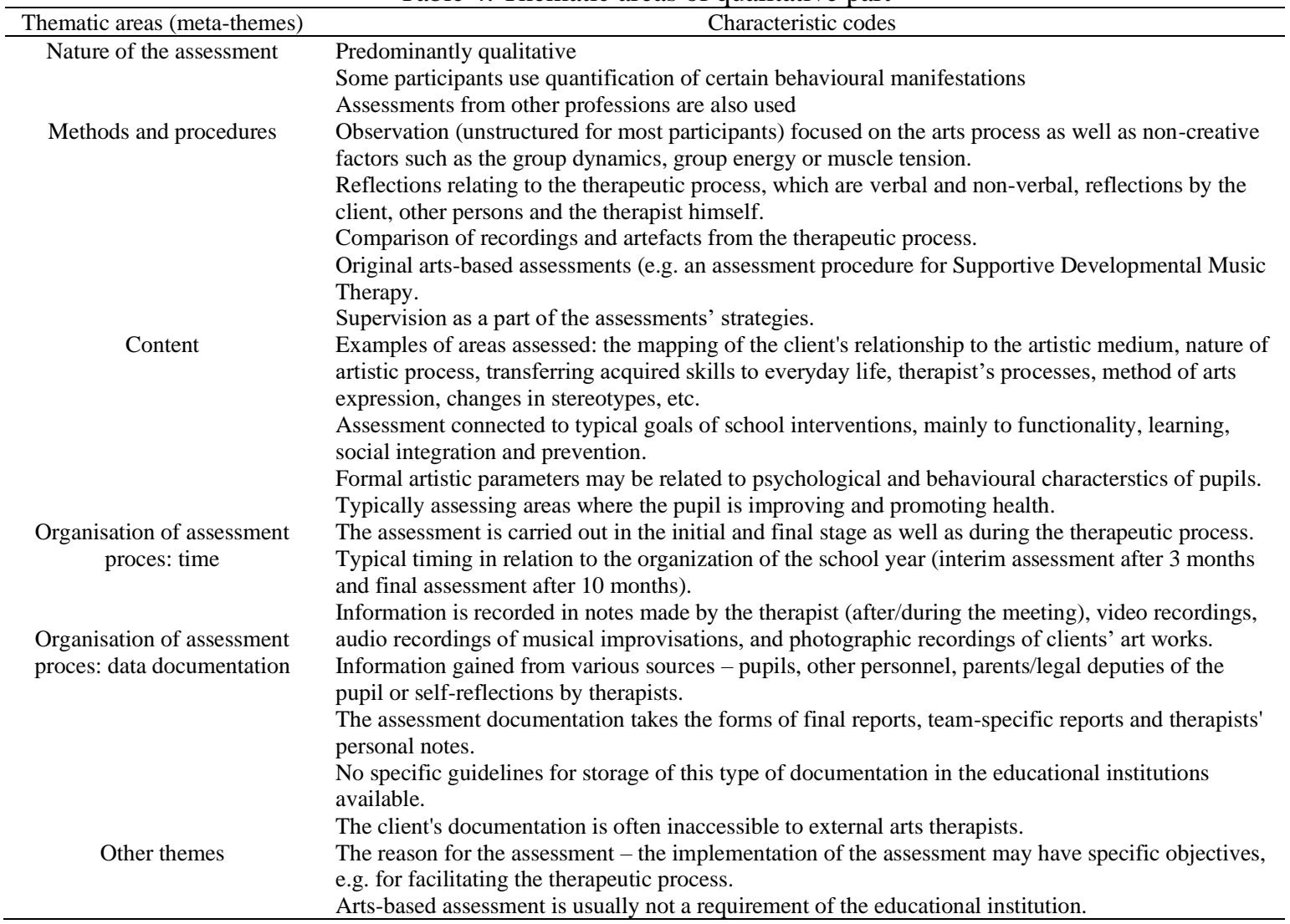

\section{CONCLUSION}

The current assessments of the Czech arts therapists are predominantly qualitative and humanistic in nature and most frequently fall within the category of therapeutic assessments. In the quantitative analyses, most factors are associated with the therapeutic relationship and the therapeutic aspects of artistic means. The least impact is seen in specialised areas of the assessments, which are typical, for example, for specific approaches (e.g. psychodynamic) or types of clientele (e.g. with neurological problems).

The assessment methods have mainly reflexive and observational form and therapists use mostly non-standardised assessments. With regards to assessment in educational institutions, only minimal differences have been found between therapists from educational institutions and other institutions/whole sample. Educational institutions may influence the assessment process by its content (objectives closely connected to the curriculum as learning or social integration), and by the organisation of the process, which is related to the organisation of the school year. Regarding current inclusive trends in Czech educational institutions, it may be expected that arts therapists will have an important role in deepening the knowledge of pupils and their school environment, mainly of pupils with special needs. But arts therapists may respond to this role only if they are properly skilled in arts-based assessment and in translating its outcomes to pupils' parents, other teachers, and relevant school staff.

A recommendation from these findings is to focus on the implementation of different types of standardised assessments (prescriptive, evaluation, diagnostic, etc.) into therapeutic practice and the development of specific procedures on how to carry out arts-based assessment in educational environment. Increasing demands may be expected directly in educational institutions regarding evidence-based decisionmaking on the recommendation of therapy and the evaluation of different areas of the therapeutic process, especially at the moment when arts therapies begin to be a service paid from resources of the educational system. A recommendation for further research is to repeat this survey in the future and find out if the changes implemented into the process of professional education of arts therapists and their practice will have made any difference in the results. For this purpose, modification of the questionnaire "The Practice in Arts Therapies" could be made so that it is more sensitive to the content of assessment in educational environment (special questions focused on functionality, learning, social integration and prevention could be elaborated). 


\section{ACKNOWLEDGEMENTS}

This work was supported by Faculty of Education, Palacky University, Žižkovo nám. 5, Olomouc, 779 00, Czech Republic; grant number IGA_2019_004 [Research of music therapy in the development of persons with special needs].

\section{REFERENCES}

[1] Betts D., "Art therapy assessment and rating instruments: Do they measure up?" The Arts in Psychotherapy, vol. 33, no. 5, pp. 422-433, 2006.

[2] Cripps C., Tsiris G., and Spiro N., Outcome measures in music therapy: A resource developed by the Nordoff Robbins research team. London (GB): Nordoff Robbins, 2016.

[3] Magee WL., "Development of a music therapy assessment tool for patients in low awareness states," NeuroRehabilitation, vol. 22, no. 4, pp. 319-324, 2007.

[4] Schweizer C., Knorth EJ., van Yperen TA., and Spreen M., "Evaluating art therapy processes with children diagnosed with Autism Spectrum Disorders: Development and testing of two observation instruments for evaluating children's and therapists' behavior," The Arts in Psychotherapy, vol. 66, pp. 1-9, Nov. 2019.

[5] Gottfried T., Thompson G., Elefant C., and Gold C., "Reliability of the Music in Everyday Life (MEL) Scale: A Parent-Report Assessment for Children on the Autism Spectrum," Journal of Music Therapy, vol. 55, no. 2, pp. 133-155, 2018.

[6] Gantt L., The Formal Elements Art Therapy Scale (FEATS). In: Gussak DE., Rosal ML. The Wiley Handbook of Art Therapy. GB: John Wiley \& Sons, pp. 569-578, 2015.

[7] Yoon JY., Betts D., and Holttum S., "The bird's nest drawing and accompanying stories in the assessment of attachment security," International Journal of Art Therapy, pp. 76-87, 2019.

[8] Carpente J. and Gattino G., "Inter-rater Reliability on the Individual Music-Centered Assessment Profile for Neurodevelopmental Disorders (IMCAP-ND) for autism spectrum disorder," Nord J Music Ther, vol. 27, no. 4, pp. 297-311, 2018.

[9] Feder B. and Cruz RF., The Art and Science of Evaluation in the Arts Therapies. Springfield (IL): Charles C Thomas Publisher; 2013.

[10] Cohen BM. and Mills A., "The Diagnostic Drawing Series (DDS) at Thirty: Art Therapy Assessment and Research," In Gussac D. and Rosal ML. (Eds.) The Wiley Handbook of Art Therapy. GB: John Wiley \& Sons, pp. 558-568, 2016.

[11] Lipský M. and Kantor J., "Identification of Challenges and Strengths of Children with Special Educational Needs in Their Musical Improvisations," Clinical Psychology and Special Education, vol. 8, no. 1, pp. 188-136, 2019.

[12] Caseová C. and Dalleyová T., Arteterapie s dětmi. Praha (CZ): Portál, 1995.

[13] Hanes MJ., "Utilizing road drawings as a therapeutic metaphor in art therapy," Am J Art Ther, vol. 34, no. 1, pp. 19-23, 1995.

[14] Loewy J., "Music Psychotherapy Assessment," Music Ther Perspect, vol. 18, no. 1, pp. 47-58, 2000.

[15] Kaiser D., "Assessing Attachement with the Bird's Nest Drawing (BND)," In Gussak DE. and Rosal ML. (Eds.) The Wiley Handbook of Art Therapy. GB: John Wiley \& Sons, pp. 514-523, 2015.

[16] Levick MF. and Siegel CA., "The Levick Emotional and Cognitive Art Therapy Assessment (LECATA)," in Gussak DE. and Rosal ML. (Eds.) The Wiley Handbook of Art Therapy. GB: John Wiley \& Sons, pp. 534-549, 2015.

[17] Mattson DC. and Yang J., "The Child Therapy Tracking System (CTTS): A model for an expressive therapy electronic health record (EHR)," The Arts in Psychotherapy, vol. 40, no. 5, pp. 509-518, 2013.

[18] Kim Seong-in, Kim Jong-Hoon, and Hong Eun-joo, "A computer system for the face stimulus assessment with application to the analysis of dementia," The Arts in Psychotherapy, vol. 40, no. 2, pp. 245-249, 2013.

[19] Kim Seong-in, Ghil Ji-Ho, Choi Eun-Yeong, Kwon Ok-Soon, Kong Maria, "A computer system using a structured mandala to differentiate and identify psychological disorders," The Arts in Psychotherapy, vol. 41, no. 2, pp. 181-186, 2014.

[20] Erkkillä J., "Music Therapy Toolbox (MTTB) an improvisation analysis tool for clinicians and researchers," In Wosch T. and Wigram T. (Eds.) Microanalysis in music therapy. London (GB): Jessica Kingsley Publishers, 2007.

[21] Simpson J., "Increasing Access to Music Therapy: The Roles of Parents, Music Therapists, and AMTA," In Wilson BL. (Eds.) Models of Music Therapy Interventions in School Settings. Silver Spring (MD): American Music Therapy Association, Inc, pp. 3-14, 1996.

[22] Betz S. and Held J., Betz-Held Strengths Inventory for Children with Disabilities. Walnut Creek (CA): Walnut Creek Music Therapy, 2013.

[23] Mössler K, et al., "The Therapeutic Relationship as Predictor of Change in Music Therapy with Young Children with Autism Spectrum Disorder," J Autism Dev Disord, vol. 49, no. 7, pp. 2795-2809, 2019.

[24] Kantor J., "Specifics of arts therapies in educational institutions comparing the institutions of health care setting," Social Welfare: Interdisciplinary Approach, vol. 2, no. 7, pp. 140-154, 2017.

[25] Kantor J., Chráska M., and Ludíková L., "Czech Arts therapies in educational institutions," Education Sciences, vol. 9, no. 2, p. 82, 2019.

[26] Michalík J., Baslerová P., and Růžička M., Postoje pedagogických pracovníků k vybraným aspektům společného vzdélávání. Olomouc (CZ): Univerzita Palackého, 2018. 
[27] Karkou V. and Sanderson P., Arts therapies: A research-based map of the field, ( $1^{\text {st }}$ Edition). Edinburgh (GB): Elsevier, 2006.

[28] Hendl J., Kvalitativní výzkum. Praha (CZ): Portál, 2016.

[29] Guest G., MacQueen KM., and Namey EE., Applied Thematic Analysis. Thousand Oaks (CA): SAGE, 2012.

[30] Gibson WJ. and Brown A., Working with Qualitative Data. Thousand Oaks (CA): SAGE, 2009.

[31] Kantor J., Společné a rozdillné v uměleckých kreativních terapiích. Olomouc (CZ): Univerzita Palackého, 2016.

[32] Paisca I., Martinsone K., and Karkou V., "The Practice of Arts therapies in Latvia: Findings from a nation-Wide Survey," Proceedings of the International Scientific Conference Art Therapy: Realities and Prospects, pp. 67-75, 2013.

[33] Lištiaková I. and Valenta M., Evaluace v dramaterapii. Olomouc (CZ): Univerzita Palackého, 2015.

[34] Powell MA., Assessment in Dance/Movement Therapy Practice: A State of the Field Survey. Philadelphia (PA): Drexel University, 2008. 